\title{
Reply
}

\section{Reply to Letter}

\author{
Floris Groenendaal Peter G.J. Nikkels Maarten H. Lequin Joline L.H. de Sévaux
}

Wilhelmina Children's Hospital, Utrecht, The Netherlands

Dear editor,

In our reply we hope to convince Shelmerdine et al., all radiologists, that autopsy performed by a dedicated pathologist is still an extremely important diagnostic tool in the field of neonatology. We would like to emphasize that it still is standard clinical practice in our unit to ask permission for autopsy in all infants who died, irrespective of the cause and circumstances of death. Thereby, our rate of autopsy has been stable during the last decade at around $30 \%$.

The questions clinicians would like to have answered from the autopsy are multiple, including assessment of our diagnostic skills during admission of the patient to our neonatal intensive care unit, thereby improving our diagnostic efficacy, but also the extent of events such as hypoxia-ischemia, use of toxic substances, iatrogenic damage, or infections. Parents can be counselled after the results of the autopsy are known, followed by additional (genetic) tests if needed.

In our patients, the cause of death is almost always known since most infants in our unit die as a result of redirection of care

\section{References}

1 Snoep MC, Jansen NJ, Groenendaal F. Deaths and end-of-life decisions differed between neonatal and paediatric intensive care units at the same children's hospital. Acta Paediatr. $2018 \mathrm{Feb} ; 107(2): 270-5$.

2 Lequin MH, Huisman TA. Postmortem MR imaging in the fetal and neonatal period. Magn Reson Imaging Clin N Am. 2012 Feb; 20(1):129-43. in the presence of irreversible multi-organ injury based on extensive brain and organ imaging as well as other examinations before death [1]. Regarding our practice, we are convinced that we have dealt with an unbiased population.

In our study, the paediatric radiologist (M.H.L.) has a vast experience in paediatric imaging both during life and postmortem, and he has published on this subject [2]. Previously, we have reported that even very experienced readers of neuroimaging could not provide the detailed information of hypoxic-ischaemic lesions of full-term infants which was detected using histology [3]. Furthermore, timing of the hypoxicischaemic insult is difficult using postmortem MRI, whereas histology using specific immunohistological or histochemical staining of inflammatory processes such as CD-68 or an Acid Fuchsin Theonin stain can [4]. The example the authors addressed in their letter on the infant with congenital CMV highlights the importance of a full autopsy. In this infant, the CMV was not clinically suspected. Maternal or placental samples were not available, and even if they would have been, the full extent of neonatal involvement could be assessed only using postmortem examination since the expression of a congenital CMV infection is extremely variable [5]. Even in a study of highly skilled teams, 23 out of 146 (15.8\%) major abnormalities were not identified by postmortem magnetic resonance imaging [6].

The purpose of our paper was to describe the clinical experience of a level III neonatal intensive care unit which has been dedicated to paediatric imaging (M.H.L.), including MRI, and pathology (P.G.J.N.) for decades. We consider our observations important to advance knowledge in this field.

We do agree with the authors that development of MRI sequences and hardware, and appropriate training of staff will increase the potential of postmortem MRI [6]. However, results of larger, well-designed trials of neonatal postmortem MRI and autopsy are urgently needed before we can counsel parents during bereavement that MRI can replace autopsy.
3 Alderliesten T, Nikkels PG, Benders MJ, de Vries LS, Groenendaal F. Antemortem cranial MRI compared with postmortem histopathologic examination of the brain in term infants with neonatal encephalopathy following perinatal asphyxia. Arch Dis Child Fetal Neonatal Ed. 2013 Jul;98(4): F304-9.

4 Groenendaal F, Lammers H, Smit D, Nikkels PG. Nitrotyrosine in brain tissue of neonates after perinatal asphyxia. Arch Dis Child Fetal Neonatal Ed. 2006 Nov;91(6):F429-33.
5 Schneeberger PM, Groenendaal F, de Vries LS, van Loon AM, Vroom TM. Variable outcome of a congenital cytomegalovirus infection in a quadruplet after primary infection of the mother during pregnancy. Acta Paediatr. 1994 Sep;83(9):986-9.

6 Ashwin C, Hutchinson JC, Kang X, Langan D, Jones R, Norman W, et al. Learning effect on perinatal post-mortem magnetic resonance imaging reporting: single reporter diagnostic accuracy of 200 cases. Prenat Diagn. 2017 Jun; 37(6):566-74.

\section{KARGER}

E-Mail karger@karger.com www.karger.com/neo

\section{(c) 2019 The Author(s)}

Published by S. Karger AG, Basel

Karger

Open access

This article is licensed under the Creative Commons AttributionNonCommercial-NoDerivatives 4.0 International License (CC BY NC-ND) (http://www.karger.com/Services/OpenAccessLicense) Usage and distribution for commercial purposes as well as any distribution of modified material requires written permission.
Floris Groenendaal

Division Woman and Baby, Department of Neonatology University Medical Center Utrecht, Room number KE.04.123.1

P.O. Box 85090, NL-3508 AB Utrecht (The Netherlands)

E-Mail F.Groenendaal@umcutrecht.nl 